\title{
Introducing a New Graduate Degree in Technology Management: Program Overview and Assessment Plan
}

\section{Dr. Gonca Altuger-Genc, State University of New York, Farmingdale}

Dr. Gonca Altuger-Genc is an Assistant Professor at State University of New York - Farmingdale State College in the Mechanical Engineering Technology Department. She is serving as the MS Technology Management Graduate Program Coordinator. Her research interests are engineering education, selfdirected lifelong learning, virtual laboratories, and decision-making framework development for design and manufacturing environments.

Dr. Bahar Zoghi, State University of New York, Farmingdale 


\title{
Introducing a New Graduate Degree in Technology Management: Program Overview and Assessment Plan
}

\begin{abstract}
Offering a new graduate degree requires curriculum development, course scheduling and developing an assessment plan. A proper assessment plan ensures program success and continuous improvement. This paper provides the initial assessment plan for a new master's degree. The timeline of the proposed assessment activities is shared and the initial implementation of the assessment plan for the Spring 2019 semester is discussed. Data collection techniques and assessment benchmarks for the course level and program level assessment is provided. This study introduces the MS in Technology Management degree and focuses on the assessment of the courses and the program.
\end{abstract}

\section{Introduction}

Offering interdisciplinary graduate programs provides students a wide range of possibilities in terms of course work and hands-on learning activities. Many colleges and universities develop interdisciplinary graduate programs to meet the demand from their student body and their industry partners. Just like any other new or existing program, it is very important for interdisciplinary graduate programs to have a strong assessment plan. A proper program assessment is a multi-level activity with short-term and long-term components and ensures continuous improvement of the program. A well-established program assessment plan includes course-level and program-level assessment components [1] while the short-term plans usually include assessment of limited number of program outcomes at the course level; the long-term plans include assessment of all program outcomes over the course of multiple semesters and years.

To ensure continuous improvement, many engineering educators incorporated assessment plans and approaches into their courses. Assessing student learning at the course level has been commonly studied and reported on. Many faculty employ formative and summative assessment techniques in course assessment. A formative classroom assessment technique [2] example has been developed and incorporated to achieve ongoing course assessment for the engineering technology (ET) courses. Students' understanding of the program outcomes assessed in a Design of Mechanical Components course by incorporating formative and summative assessment techniques [3]. Formative and summative assessment approaches are also extensively used for program assessment for ABET accreditation. A study on formative versus summative assessment for a Biomedical Engineering (BME) program concluded that most of the ABET outcomes were achieved at marginal levels by the formative assessment [4]. A good assessment process at the course level includes having Course Learning Objectives and tie them to Program Learning Objectives. The faculty members teaching the course serve as experts and develop assessment tools to measure the course's Learning Objectives [5]. Course assessment is also a very important first step towards ABET program assessment activities. Many educators reported 
on the practices, strategies and tools they employed when assessing course learning outcomes. Meyer [6] reported on evaluation instrument selection and use of static versus dynamic thresholds in computer engineering courses. Sanders et.al [7] reported on assessment processes for interdisciplinary capstone projects. Beyerlein et. Al [8] developed a framework to create efficient assessment instruments that can be used to assess capstone design courses. Rowe et al. [9] highlighted the importance of assessment at the freshman level, and reported on innovative formative assessment used in a freshman level course with a focus on retention. Assessment activities are an integral part of new graduate programs, as these programs need to set-up procedures and employ appropriate tools to establish assessment plans. Sathyamoorthy [10] reported on the development of a graduate program in Control Systems Engineering and provided assessment items for program quality assessment, student performance assessment and measurement instruments used in collecting the assessment data. Gharabagi et al. [11] shared Master of Sustainability degree experience, and informed that continuous assessment is achieved by continuously assessing both at the course and at the program level. Latif and Dyrenfurth [12] developed an assessment procedure with instrument selection for a Weekend Master's Program. Gross et al. [13] shared the development of a Structural Engineering Professional Master's degree program and provided the market assessment to identify the key features that add value to the program. The implementation of these different tools and methodologies show the variety of different approaches that are implemented to assess graduate level programs.

In this study, the authors report on the new MS Technology Management degree offered at Farmingdale State College and will provide an initial assessment plan and report on the assessment activities that are being carried out during Spring 2019 semester.

\section{Program Outcomes}

The MS in Technology Management program at Farmingdale State College has two tracks [14]:

- "Track I: Electrical and Mechanical

- Track II: Construction Management"

MS in Technology Management program outcomes [15] are listed as:

1. "Graduates will have knowledge and competency in the field of technology management with an emphasis on engineering technologies.

2. Graduates will have the knowledge and skills necessary to be imaginative, critical thinkers who are able to discover problems and questions, develop logical answers, and apply effective solutions in the practice of technology management.

3. Graduates will have knowledge of ethical behavior in professional positions in all aspects of technology management.

4. Graduates will have competency in the management and leadership of technology in global industry.

5. Graduates will have an awareness of diversity in the various fields of technology.

6. Graduates will have skill to evaluate technical management issues in the context of ethical, technological, structural, cultural, human and environmental factors.

7. Graduates will have skill to develop and foster critical thinking, analysis, planning, and communication. 
8. Graduates will have knowledge and skills in the improvement of productivity, quality control, and competitiveness in all aspects of technology management through collaborative relationships with regional industries."

The program outcomes are an important part of any program (graduate or undergraduate), as they are comprehensive and identify the critical skills, knowledge and competency students will gain upon completion of the program. To ensure continuous improvement of any program, it is crucial to assess program outcomes to identify how they are achieved and if they aren't achieved, what steps need to be taken to achieve them. The assessment of the program outcomes can be completed directly through the courses offered in the program and indirectly through student surveys. Having an assessment procedure is important for successful program assessment.

\section{Program Assessment}

Farmingdale State College has an established assessment procedure for its undergraduate programs, and the MS Technology Management program will follow the college's existing program assessment procedure. The assessment procedure requires academic departments to prepare annual assessment plans and reports.

Since MS Technology Management is a new program, the first assessment plan was prepared and the following are established:

i) Mapping of program outcomes to courses

ii) Preliminary program assessment timeline

The following subsections on Program Level Assessment Activities and Course Level Assessment Activities will discuss the above mapping and timeline in detail.

\section{Program Level Assessment Activities}

The program level assessment provides a longitudinal assessment activity, where all the courses in the program are assessed over the course of multiple semesters. Program level assessment activities are very important as they tie the whole program together by having different courses meeting different program outcomes. It is usually not very common to have all the courses meet all the program outcomes, with the exception of capstone courses as project or thesis. Based on the course offering schedule, the proposed assessment plan for the MS Technology Management program is to assess at least two program outcomes through two different courses each semester, with the goal of achieving the assessment of all program outcomes over the course of 4 semesters. The details and the timeline of the proposed program assessment activities are shared in Table 1. According to the proposed assessment plan, Program Outcome 1: "Graduates will have knowledge and competency in the field of technology management with an emphasis on engineering technologies" [15] will be assessed in Spring 2019 semester through ETM 513 Computer Applications in Engineering Technology course and in Spring 2021 semester through both ETM 513 and ETM 531 Construction Cost Analysis and Advanced Estimating courses. With the proposed assessment plan timeline, the program assessment is currently divided into 2-year sub-plans. By the end of the initial 2-year part of the assessment plan, all program outcomes have been assessed by at least one course, and in the second 2-year part of the assessment plan, all program outcomes will be assessed by at least two courses. This 
gradual increase will ensure $(i)$ continuity in the assessment process from first 2-year sub-plan to second 2-year sub-plan by assessing the same courses, and (ii) variety in the assessment process by adding new courses to the assessment plan from the first 2-year sub-plan to second 2-year sub-plan. The future 2-year sub-plans are expected to build on the previous sub-plans and is also expected to include a comparative analysis of the assessment outcomes.

Table 1. Proposed Program Assessment Timeline

\begin{tabular}{|c|c|c|}
\hline Course Number and Title & Semester & $\begin{array}{l}\text { Program } \\
\text { Outcomes }\end{array}$ \\
\hline ETM 513 - Computer Applications in Engineering Technology & \multirow{2}{*}{ Spring 2019} & 1 \\
\hline ETM 503 - Research Methods & & 7 \\
\hline ETM 501 - Engineering Quality Management and Reliability & \multirow{2}{*}{ Fall 2019} & 4 \\
\hline ETM 511 - Nanotechnology Principles and Applications & & 2 \\
\hline BUS 504 - Technology Management Ethics and Policies & \multirow{2}{*}{ Spring 2020} & 3 \\
\hline ETM 530 - Residential Development Management & & 8 \\
\hline BUS 502 - Project Management & \multirow{2}{*}{ Fall 2020} & 6 \\
\hline BUS 532 - Legal Aspects of Construction Management & & 5 \\
\hline $\begin{array}{l}\text { ETM } 503 \text { - Research Methods } \\
\text { ETM } 510 \text { - Energy and Power Management Analysis }\end{array}$ & \multirow[b]{2}{*}{ Spring 2021} & 7 \\
\hline $\begin{array}{l}\text { ETM } 513 \text { - Computer Applications in Engineering Technology } \\
\text { ETM } 531 \text { - Construction Cost Analysis and Advanced Estimating }\end{array}$ & & 1 \\
\hline $\begin{array}{l}\text { ETM } 511 \text { - Nanotechnology Principles and Applications } \\
\text { ETM } 520 \text { - Control Systems Management }\end{array}$ & \multirow[t]{2}{*}{ Fall 2021} & 2 \\
\hline $\begin{array}{l}\text { ETM } 501 \text { - Engineering Quality Management and Reliability } \\
\text { ETM } 521 \text { - Semiconductor Devices and Integrated Circuits }\end{array}$ & & 4 \\
\hline
\end{tabular}

\section{Course Level Assessment Activities}

These are the assessment activities faculty employ and incorporate into their courses to assess course learning outcomes. At the course assessment level, usually homework, quiz, mid-term exam, project and final exam assignments are used to measure specific course outcomes and students' understanding of these outcomes. The outcomes of the course level assessment activities are expected to build the foundation of the program level assessment.

ETM 513 - Computer Applications in Engineering Technology course is examined in this study to demonstrate the course level assessment activities that will be carried out. One of the course learning outcomes of ETM 513 Computer Applications in Engineering Technology course "Students will learn to create valid and reliable computer models with proper constraints \& loads for simulation" is assessed through technical laboratory reports. The criterion for success 
is set to $80 \%$ of the students in the class receiving 80 or higher in the laboratory reports. It is also a good practice to have more than one method of assessment for the course learning outcomes. For the same course, the same student outcome will also be assessed through the Final Exam. A question in the final exam will focus on creating a simulation model with loads and constraints to carry out appropriate computational analysis. An added benefit of employing two means of assessment for the same course learning outcome is: during the semester a formative assessment activity is completed through the laboratory report, where at the end of the semester a summative assessment activity is completed through the final exam. The course instructor can observe and report on the results of the formative and summative assessment outcomes and document the continuity in learning as well as propose methods and approaches to continuously improve the course.

\section{Conclusions and Future Work}

Currently the preliminary assessment plan for the next 6 semesters are developed. By the end of Spring 2019 semester, the proposed assessment plan will be updated to include recommendations, suggestions along with assessment outcomes from the Spring 2019 semester. The outcomes will be then used to create a starting point for the course and program outcomes. The assessment data will be used for continuous improvement and comparative analysis of the assessment outcomes in the future semesters.

Upon completion of the initial assessment plan in Spring 2019 semester, future work will review mapping of the program's outcomes to the college's goals and objectives. And development of additional assessment activities will be investigated. In addition, in the future semesters, additional technical elective courses are planned to be offered. Assessment plans for these courses will be developed and program assessment timeline will be updated to include these technical elective courses.

\section{References}

1. G. Altuger-Genc and B.Zoghi, 2018, "A Comprehensive Approach to Assessment Plan Development for an Interdisciplinary Graduate Degree", Proceedings of the 2018 ASEE Northeast Section Conference, April 27-28, 2018, West Hartford, CT

2. A. Aghayere 2005, "The Case for Ongoing Student Course Assessment", Proceedings of the 2005 ASEE Annual Conference and Exposition, June 12-15, 2005, Portland, OR

3. K. Nasr, R. Echempati, and A. Mazzei, 2004, "Student Understanding of Program Outcomes Through Formative and Summative Course Level Assessment", Proceedings of the 2004 ASEE Annual Conference and Exposition, June 20-23, 2004, Salt Lake City, UT

4. D. Piovesan and K.M. Vernaza, 2015, "Formative vs. Summative ABET Assessment: A Comprehensive Graphic Representation for a new BME Program", Proceedings of the 2015 Annual ASEE Conference and Exposition, June 14-17, 2015, Seattle, WA 
5. J. Duke and D. Morris, 2002, "Assessing Undergraduate Mechanics Courses", Proceedings of the 2002 ASEE Annual Conference and Exposition, June 16-19, 2002, Montreal, Canada

6. D. Meyer,2006, "Strategies for Assessing Course Specific Outcomes", Proceedings of the 2006 ASEE Annual Conference and Exposition, June 18-21, 2006, Chicago, IL

7. M. Sanders, M. Thompson, M. El-Sayed, L. King, and M. Lindquist, 2006, "Assessing Interdisciplinary Engineering Capstone Project" Proceedings of the 2006 ASEE Annual Conference and Exposition, June 18-21, 2006, Chicago, IL

8. S. Beyerlein, D. Davis, P. Thompson, M. Trevisian, and O. Harrison, 2006, "Assessment Framework for Capstone Design Courses", Proceedings of the 2006 ASEE Annual Conference and Exposition, June 18-21, 2006, Chicago, IL

9. A. Mahadevan-Jansen, C. Rowe, and S. Klein-Gardner, 2005, "Assessing A Freshman Engineering Course", Proceedings of the 2005 ASEE Annual Conference and Exposition, June 12-15, 2005, Portland, OR

10. M. Sathyamoorthy, 2002, "An Interdisciplinary Graduate Program at Wvutech", Proceedings of the 2002 ASEE Annual Conference and Exposition, June 16-19, 2002, Montreal, Canada

11. R. Gharabagi, H.S. Mallikarjuna, and D.E. Webb, 2012, “An Interdisciplinary Master's of Sustainability Program", Proceedings of the 2012 ASEE Annual Conference and Exposition, June 10-13, 2012, San Antonio, TX

12. N. Latif and M. Dyrenfurth, 2002, "Assessment of an Innovative Master's Degree", Proceedings of the 2002 ASEE Annual Conference and Exposition, June 16-19, 2002, Montreal, Canada

13. J. Gross, D.M. Mohr and S. Pessiki, 2012, "Creation of a Structural Engineering Professional Master's Degree Program", Proceedings of the 2012 ASEE Annual Conference and Exposition, June 10-13, 2012, San Antonio, TX

14. https://www.farmingdale.edu/academics/curriculum/ms-technology-management.shtml Accessed on 04/29/2019

15. Farmingdale State College, 2018-2019 College Catalog, https://www.farmingdale.edu/registrar/pdf/catalog-18-19.pdf Accessed on 04/29/2019 